\title{
Enantioselective resolution of biologically active dipeptide analogs by high-performance liquid chromatography applying Cinchona alkaloid-based ion-exchanger chiral stationary phases
}

\author{
Attila Bajtai ${ }^{a}$, István Ilisz ${ }^{a}$, Dian H.O. Howan ${ }^{b}$, Gábor K. Tóth ${ }^{b}$, Gerhard K.E. Scribac, \\ Wolfgang Lindner ${ }^{\mathrm{d}, *}$, Antal Péter ${ }^{\mathrm{a}, * *}$ \\ a Institute of Pharmaceutical Analysis, Interdisciplinary Excellence Centre, University of Szeged, H-6720 Szeged, Somogyi u. 4, Hungary \\ ${ }^{\mathrm{b}}$ Department of Medical Chemistry, University of Szeged, H-6720 Szeged, Dóm tér 8, Hungary \\ ${ }^{\mathrm{c}}$ Department of Pharmaceutical and Medicinal Chemistry, School of Pharmacy, Friedrich Schiller University Jena, Philosophenweg 14, D-07743 Jena, Germany \\ ${ }^{\mathrm{d}}$ Department of Analytical Chemistry, University of Vienna, Währinger Strasse 38, 1090 Vienna, Austria
}

\section{A R T I C L E I N F O}

\section{Article history:}

Received 23 July 2019

Revised 24 September 2019

Accepted 26 September 2019

Available online 27 September 2019

\section{Keywords:}

High-performance liquid chromatography Dipeptides

Cinchona alkaloid-based weak

anion-exchanger and zwitterionic chiral

stationary phases

\begin{abstract}
A B S T R A C T
Sixteen pairs of enantiomeric dipeptides were separated on four chiral ion-exchanger-type stationary phases based on Cinchona alkaloids. Anion-exchangers (QN-AX, QD-AX) and zwitterionic phases $\left[\mathrm{ZWIX}(+)^{\mathrm{TM}}\right.$ and $\left.\mathrm{ZWIX}(-)^{\mathrm{TM}}\right]$ were studied in a comparative manner. The effects of the nature and concentrations of the mobile phase solvent components and organic salt additives on analyte retention and enantioseparation were systematically studied in order to get a deeper insight into the enantiorecognition mechanism. Moreover, experiments were performed in the temperature range $10-50{ }^{\circ} \mathrm{C}$ to calculate thermodynamic parameters like changes in standard enthalpy, $\Delta\left(\Delta \mathrm{H}^{\circ}\right)$, entropy, $\Delta\left(\Delta S^{\circ}\right)$, and free energy, $\Delta\left(\Delta G^{\circ}\right)$ on the basis of van't Hoff plots derived from the $\ln \alpha v s .1 / T$ curves. Elution sequences of the dipeptides were determined in all cases and, with a few exceptions, they were found to be opposite on the pseudoenantiomeric stationary phases as of QN-AX/QD-AX and of ZWIX(+) and ZWIX(-). The stereoselective retention mechanism is based on electrostatically driven intermolecular interactions supported by additional interaction increments mainly determined by the absolute configuration of the chiral $\mathrm{C} 8$ and C9 atoms of the quinine and quinidine moieties.
\end{abstract}

(c) 2019 Elsevier B.V. All rights reserved.

\section{Introduction}

Peptides are an important class of natural compounds with diverse biological functions. Many peptides possess pharmacological activity, e.g., as hormones, enzyme inhibitors, receptor ligands, antibiotics, neurotransmitters, etc. Peptide analogs and peptidomimetics play an important role as pharmaceutical drugs. Most of these therapeutic peptides and their analogs are structurally related to each other. The pharmacological activity and/or stability are often related to the stereochemistry of the compounds. In addition, racemization of amino acid residues is a frequent side reaction in peptide synthesis [1,2]. The substitution of L-amino acids by the corresponding D-amino acids is an approach applied frequently

\footnotetext{
* Corresponding authors.

** Co-corresponding author.

E-mail addresses: wolfgang.lindner@univie.ac.at (W. Lindner), apeter@chem.uszeged.hu (A. Péter).
}

to increase metabolic stability and/or pharmacological activity. For instance, increased bioavailability has been observed for chemically modified Met-enkephalin and Leu-enkephalin [3]. Moreover the partial isomerization of certain amino acids in L-amino acidbased peptides has been shown to drastically alter biological activities of the peptides [4].

In this context, suitable enantio- and diastereoselective techniques are capable of assessing the absolute configuration of the amino acid residues and control the stereochemical purity of (therapeutic) peptides and peptidomimetics either in intact or digested form. The use of such methods is often necessary in the chemical and pharmaceutical industry [5]. Complete structure elucidation, however, requires the identification of the absolute configuration of the chiral building blocks. Since most peptides are rather hydrophilic compounds and the respective diastereomer separations may be accomplished with achiral phases under RP-LC conditions, chiral stationary phases (CSPs) may provide a better or complementary selectivity especially in combination with mass spectrometry (LC-MS techniques). There are only a few enantio- 

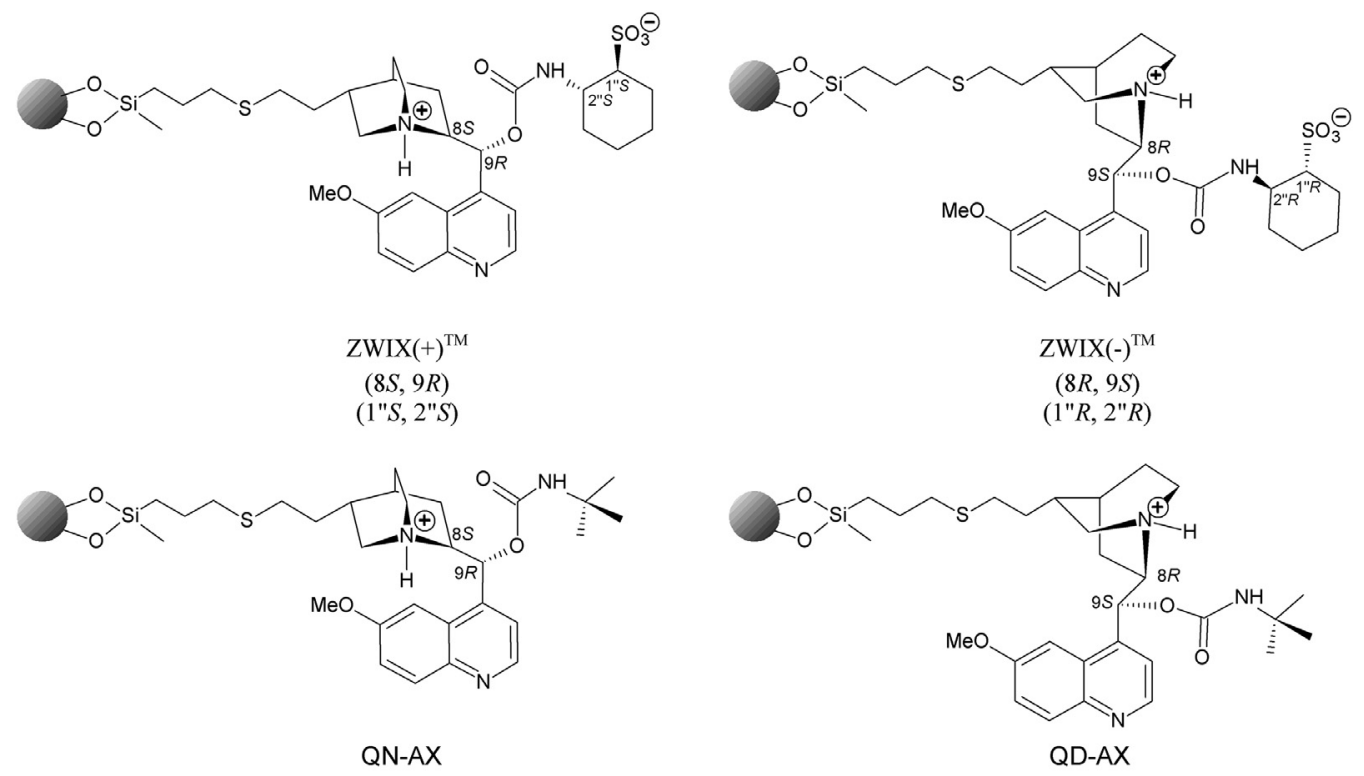

QN-AX

$(8 R, 9 S)$

Fig. 1. Structure of Cinchona alkaloid-based selectors.

and stereoselective methods described for the separation of free (non-derivatized) peptides on CSPs. In this context peptide enantiomer and diastereomer separations have been reported, for example, with chiral ligand-exchange-type methodologies [6], chiral crown ether-based CSPs [7], cyclodextrin-type CSPs [8,9] or macrocyclic glycopeptide-type CSPs such as teicoplanin, teicoplanin aglycon [10-13], and ristocetin A [14]. Macrocyclic glycopeptides as chiral selectors were also applied in hydrophilic interaction liquid chromatography (HILIC) [15], and applications of superficially porous particle-based macrocyclic glycopeptide-type CSPs have recently been reported [16].

In addition to the above-mentioned CSPs, weak anionexchangers (WAX) based on Cinchona alkaloid quinine and quinidine modified by tert-butyl carbamate are frequently applied in polar-ionic mode (PIM) under slightly acidic conditions for the separation of $N^{\alpha}$-protected amino acids and peptides [17-19]. Zwitterionic chiral selectors (ZWIX) and CSPs thereof prepared from Cinchona alkaloids and aminocyclohexanesulfonic acids operating under weekly acidic conditions have been shown to facilitate the retention of non-derivatized amphoteric molecules as free amino acids and small peptides [17,20-24]. On ZWIX CSPs, the ampholytic analytes are retained by the simultaneous formation of double ion pairs between the acidic and basic terminus of the analytes and the positively and negatively charged groups (sites) of quinine or quinidine aminocyclohexanesulfonic acid carbamate moieties. Based on this concept, derivatization of the peptide $N$ or $C$ terminus is no longer necessary, and the potential risk of errors (like racemization, kinetic resolution, incomplete derivatization, etc.) can be neglected.

In this contribution, we present and discuss the separation performance of Cinchona alkaloid-based chiral zwitterionic $\left[\mathrm{ZWIX}(+)^{\mathrm{TM}}\right.$ and $\left.\mathrm{ZWIX}(-)^{\mathrm{TM}}\right]$ and chiral anion-exchanger (QN-AX, QD-AX) type CSPs (Fig. 1) for the enantio- and diastereoselective resolution of a set of non-derivatized dipeptides, summarized in Table 1 and depicted in Fig. 2. Emphasis is drawn to the effects of mobile phase compositions, counter-ion content, and temperature including the elution order of the analytes by changing the core structure element of the chiral selectors of the CSPs from quinine to quinidine. The enantio- and diastereoselectivity of the CSPs and
Table 1

Sequence and configuration of amino acids of the investigated dipeptides.

\begin{tabular}{|c|c|c|c|}
\hline 1-LL & H-L-Ala-L-Ala-OH & 1-DD & H-D-Ala-D-Ala-OH \\
\hline 1-LD & H-L-Ala-D-Ala-OH & 1-DL & H-D-Ala-L-Ala-OH \\
\hline 2-LL & H-L-Ala-L-Phg-OH & 2-DD & H-D-Ala-D-Phg-OH \\
\hline 3-LL & H-L-Ala-L- $\beta$-Phe-OH & 3-DD & H-D-Ala-D- $\beta$-Phe-OH \\
\hline 4-LL & H-L-Ala-L-Phe-OH & 4-DD & H-D-Ala-D-Phe-OH \\
\hline 4-LD & H-L-Ala-D-Phe-OH & 4-DL & H-D-Ala-L-Phe-OH \\
\hline 5-LL & H-L-Ala-L-homoPhe-OH & 5-DD & H-D-Ala-D-homoPhe-OH \\
\hline $6-\mathrm{L}$ & H- $\beta$-Ala-L-Phe-OH & 6-D & $\mathrm{H}-\beta$-Ala-D-Phe-OH \\
\hline 7-LL & H-L-Ala-L-Phe-OMe & 7-DD & H-D-Ala-D-Phe-OMe \\
\hline 8-LL & H-L-Ala-L-Phe- $\mathrm{NH}_{2}$ & 8-DD & H-D-Ala-D-Phe- $\mathrm{NH}_{2}$ \\
\hline 9-LL & H-L-Ala-L-Tyr-OH & 9-DD & H-D-Ala-D-Tyr-OH \\
\hline 10-LL & $\mathrm{H}-\mathrm{L}-\mathrm{Ala}-\mathrm{L}-4-\mathrm{NO}_{2} \mathrm{Phe}-\mathrm{OH}$ & 10-DD & $\mathrm{H}-\mathrm{D}-\mathrm{Ala}-\mathrm{D}-4-\mathrm{NO}_{2}$ Phe-OH \\
\hline 11-LL & H-L-Ala-L-Trp-OH & 11-DD & H-D-Ala-D-Trp-OH \\
\hline 12-L & H-Gly-L-Phe-OH & 12-D & H-Gly-D-Phe-OH \\
\hline 13-L & H-L-Phe-Gly-OH & 13-D & H-D-Phe-Gly-OH \\
\hline 14-LL & H-L-Phe-L-Ala-OH & 14-DD & H-D-Phe-D-Ala-OH \\
\hline 14-LD & H-L-Phe-D-Ala-OH & 14-DL & H-D-Phe-L-Ala-OH \\
\hline 15-LL & H-L-Lys-L-Phe-OH & 15-DD & H-D-Lys-D-Phe-OH \\
\hline 16-LL & H-L-Leu-L-Leu-OH & 16-DD & H-D-Leu-D-Leu-OH \\
\hline 16-LD & H-L-Leu-D-Leu-OH & 16-DL & H-D-Leu-L-Leu-OH \\
\hline
\end{tabular}

the elution orders by changing from quinine to quinidine moiety of the selectors are demonstrated.

\section{Experimental}

\subsection{Chemicals and reagents}

The four stereoisomers (LL, DD, LD, and DL) of dipeptides 1 and 16, as well as compounds 4-LL, 4-DD, 8-LL, 9-LL, 11-LL, 12D, and 15-LL were purchased from Bachem (Bubendorf, Switzerland), while 12-L was from Fluka Chemie (Buchs, Switzerland) (Table 1 and Fig. S1). 13-L, 13-D, 14-LD, 14-DL were synthetized according to the solid-phase protocol applying Fmoc chemistry. Briefly, the appropriate Fmoc-protected C-terminus amino acid was attached to 2-chlorotrityl resin. After the deprotection by piperazine treatment, the Fmoc-protected amino acid was coupled with diisopropylcarbodiimide and hydroxybenzotriazole. Finally, the Fmoc-protected dipeptides were detached from the resin by treatment with $1.0 \%$ trifluoroacetic acid in dichloromethane 
$\begin{array}{lllll}1 & 2 & 3 & 4\end{array}$<smiles>CC(N)C(=O)N[C@@H](C)C(=O)OC(C)C(=O)N[C@@H](CC(=O)O)c1ccccc1C(=O)NC(C)C(=O)NC(C)C(=O)N[C@@H](Cc1ccccc1)c1ccccc1</smiles>

5

6

7

8<smiles>CC(N)C(=O)N[C@@H](Cc1ccccc1)C(=O)N[C@@H](Cc1ccccc1)C(N)=O</smiles>

9

10

11

12<smiles>CC(N)C(=O)N[C@@H](Cc1ccc(O)cc1)C(=O)O</smiles>

13

14

15

16<smiles>NC(Cc1ccccc1)C(=O)NCC(=O)O</smiles><smiles>CC(NOC(=O)C(N)Cc1ccccc1)C(=O)O</smiles><smiles>CC(C)CC(N)C(=O)NC(CC(C)C)C(=O)O</smiles>

Fig. 2. Structures of dipeptides.

[25]. All other dipeptides not available commercially were prepared according to standard peptide chemistry procedures, namely, by reacting the respective $N$-benzyloxycarbonyl-protected amino acid $N$-hydroxysuccinimide with the second amino acid in dimethylformamide followed by hydrogenolytic deprotection [26]. Dipeptides thus prepared were identified by mass spectrometry.

Acetonitrile $(\mathrm{MeCN})$, methanol $(\mathrm{MeOH})$, tetrahydrofuran (THF) of HPLC grade, and diethylamine (TEA), formic acid (FA), acetic acid $(\mathrm{AcOH})$ of analytical reagent grade were purchased from VWR International (Radnor, PA, USA). Ultrapure water was obtained from Ultrapure Water System, Puranity TU UV/UF (VWR International bvba, Leuven, Belgium).

\subsection{Apparatus and chromatography}

Two chromatographic systems were applied. The Waters Breeze system consisted of a 1525 binary pump, a 487 dual-channel ab- sorbance detector, a 717 plus autosampler and Empower 2 data manager software (Waters Chromatography, Milford, MA, USA). A Lauda Alpha RA8 thermostat (Lauda Dr. R. Wobser Gmbh, Lauda-Königshofen, Germany) was used for thermostating the columns.

The 1100 Series HPLC system from Agilent Technologies (Waldbronn, Germany) consisted of a solvent degasser, a pump, an autosampler, a column thermostat, a multiwavelength UV-Vis detector, and a corona-charged aerosol detector from ESA Biosciences, Inc. (Chelmsford, MA, USA). Data acquisition and analysis were carried out with ChemStation chromatographic data software from Agilent Technologies.

The commercially available Cinchona alkaloid-based Chiralpak ZWIX $(+)^{\mathrm{TM}}$ and ZWIX $(-)^{\mathrm{TM}}(150 \times 3.0 \mathrm{~mm}$ I.D., 3- $\mu \mathrm{m}$ particle size $)$ and Chiralpak QN-AX and QD-AX $(150 \times 3.0 \mathrm{~mm}$ I.D., 3- $\mu \mathrm{m}$ particle size) columns were gifts from Chiral Technologies Europe (Illkirch, France). 


\section{Results and discussions}

As can be extracted from Fig. 2 the chromatographically screened dipeptides 1-11 contain Ala-or $\beta$-Ala-at the $N$-terminus and dipeptides 2-11 contain different aromatic amino acids such as Phe-analogs, Trp-and Tyr-at the C-terminus. Peptides 13 and $\mathbf{1 4}$ possess Phe-at the $N$-terminus, while dipeptides 1 (Ala-Ala) and $\mathbf{1 6}$ (Leu-Leu) are aliphatic dipeptides. These structural differences may have an effect on the chromatographic elution order to some extent in case of the employed pseudoenantiomeric cWAX and ZWIX type CSPs.

\subsection{Mobile phase selection}

In the development of the HPLC method, regardless of the nature of the investigated CSPs, variation of the mobile phase composition is usually the first choice to achieve stereoisomer resolutions. In the zwitterionic Cinchona alkaloid-based CSPs (Fig. 1), the weak tertiary amino group ( $\left.\mathrm{p} K_{\mathrm{a}} \sim 9.5\right)$ of quinuclidine acts as an anion-exchanger in its protonated state, while the strong sulfonic acid group $\left(\mathrm{p} K_{\mathrm{a}} \sim 1.0\right)$ functions as a cation-exchanger site. As shown earlier, nonaqueous polar organic solvents in combination with base and acid modifiers proved to be the preferential mobile phases for the separation of zwitterionic solutes on these CSPs [17]. Due to the polar protic character, $\mathrm{MeOH}$ weakens the $\mathrm{H}$-bonding interactions. MeCN as an aprotic polar solvent, in turn, strengthens the ionic interactions, but weakens aromatic $\pi-\pi$ interactions. This solvent combination proved to be the best choice due to the suppression of nonspecific hydrophobic interactions with the CSP, thereby enhancing enantioselectivity $[17,24]$. Moreover, the anions and cations of the acid and base additives have great effects on the elution strength of the mobile phase, inversely acting as displacers at the cationic- and/or anionic-exchanger sites of the ionexchange-type CSP.

For the selected Cinchona alkaloid-based CSPs, namely on $\mathrm{ZWIX}(+)^{\mathrm{TM}}, \mathrm{ZWIX}(-)^{\mathrm{TM}}, \mathrm{QN}-\mathrm{AX}$, and QD-AX, first, the influence of the composition of bulk solvents on chromatographic parameters was investigated using the following selected analytes: [H-AlaPhg-OH (2), H- $\beta$-Ala-Phe-OH (6), H-Ala-Tyr-OH (9), H-Ala-Trp-OH (11), and $\mathrm{H}$-Leu-Leu-OH (16)]. In the presence of protic MeOH, the amount of the aprotic $\mathrm{MeCN}$ in the solvent mixture was increased, while keeping the acid to base ratio of the additives (25 mM DEA and $50 \mathrm{mM} \mathrm{FA}$ ) constant. The respective experimental results are summarized in Fig. 3. Upon changing the bulk solvent composition, the acid-base equilibrium and proton activity may also change, but weakly acidic conditions were ensured throughout the chromatographic separation process. The retention of zwitterionic dipeptides increased with increasing the $\mathrm{MeCN}$ content in the mobile phase, which corroborates the effect of $\mathrm{MeCN}$ in decreasing the solvation shell of all charged sites of the selector (SO) and selectand (SA), thus leading to an enhanced electrostatic intermolecular attraction (Fig. 3). For the $\mathrm{MeOH} / \mathrm{MeCN}$ range investigated, enantioselectivity decreased slightly (except for analyte $\mathbf{6}$ on $\mathrm{ZWIX}(+)^{\mathrm{TM}}$, and $\mathbf{1 1}$ on $\mathrm{QD}-\mathrm{AX}$ ), while the increase in $\mathrm{MeCN}$ content resulted in either an increase or decrease in resolution. Column efficiencies (illustrated as plate numbers in Table 2) varied in a rather scattered way. In several cases plate numbers followed the same trend that observed for resolution, while in other cases they changed oppositely, suggesting that selectivity and retention factors significantly affect resolution. A comparison of the chromatographic parameters for the selected dipeptides possessing either an aromatic (2, 6, 9 and 11) or an aliphatic (16) amino acid at the $C$-terminus revealed that $k_{1}$ values were the lowest for dipeptides possessing an aliphatic amino acid at the $C$-terminus. However, the enantioselectivity and resolution on QN-AX and QD-AX were most often enhanced for dipeptides possessing aliphatic amino acids relative to aromatic amino acids, which indicates that $\pi-\pi$ interactions between selector and dipeptide are not prominent in the present case (Fig. 3).

On ZWIX $(+)^{\mathrm{TM}}$ and ZWIX(- $)^{\mathrm{TM}}$ CSPs for analyte $\mathbf{1 1}$ the effect of $\mathrm{MeCN}$ content was investigated for the entire $\mathrm{MeOH} / \mathrm{MeCN}$ range from $100 / 0$ to $0 / 100(v / v)$. Results are depicted in Fig. S1. Above $80 \mathrm{v} \% \mathrm{MeCN} k_{1}$ values enlarged extremely $\left(k_{1}>100\right)$, while a drastic decrease was observed for enantioselectivity and resolution at $100 \mathrm{v} \% \mathrm{MeCN}$.

As reported earlier, applying $\mathrm{MeOH} / \mathrm{THF}$ as bulk solvent instead of $\mathrm{MeOH} / \mathrm{MeCN}$ resulted in an improvement in enantioselectivity and resolution in some cases [27,28]. In the present study, the chromatographic behavior of analytes $2,6,9,11$, and 16 on the ZWIX $(+)^{\mathrm{TM}}, \mathrm{ZWIX}(-)^{\mathrm{TM}}$, QN-AX and QD-AX CSPs was investigated as a function of the THF content in $\mathrm{MeOH}$. As depicted in Fig. S2, the $\mathrm{MeOH} / \mathrm{THF}$ mobile phase containing $25 \mathrm{mM}$ DEA and $50 \mathrm{mM}$ FA yields similar tendencies as observed in the case of $\mathrm{MeOH} / \mathrm{MeCN}$ bulk solvents. The selectivity, resolution and column efficiencies did not improved significantly. The $k_{1}$ values slightly decreased, while selectivity and resolution (with a few exceptions) increased with increasing $\mathrm{MeOH}$ content. In most of the cases plate numbers followed the same trends, as observed for resolutions. Similar to $\mathrm{MeOH} / \mathrm{MeCN}$, bulk solvent on $\mathrm{ZWIX}(+)^{\mathrm{TM}}$ and $\mathrm{ZWIX}(-)^{\mathrm{TM}}$ CSPs, the highest selectivity was observed for H-Ala-Trp-OH, while on QN-AX and QD-AX CSPs, H-Leu-Leu-OH exhibited the highest enantioselectivity. The higher content of protic $\mathrm{MeOH}$ progressively weakens the ionic interactions between the peptides and the selectors, and the enhanced solvation of polar dipeptides results in a decrease of retention. On the basis of these results, all further experiments were carried out with a mixture of $\mathrm{MeOH} / \mathrm{MeCN}$ as bulk solvent.

\subsection{Effects of acid and base additives}

Non-aqueous polar organic solvents in combination with acid and base additives both acting as co- and counter-ions for ionexchange-type systems greatly influence the solvation effects and hence the strength of the electrostatic interaction (ion-exchange) processes between the zwitterionic selector and the ionic analytes. The anions and cations of acid and base additives act as displacers at the cationic and anionic exchanger sites of zwitterionic selectors [29].

Investigations of the effects of acid and/or base additives for $\mathrm{H}$ Ala-Trp-OH (11) on ZWIX $(+)^{\mathrm{TM}}$ and ZWIX $(-)^{\mathrm{TM}}$ CSPs were carried out in the mobile phase $\mathrm{MeOH} / \mathrm{MeCN}(50 / 50 v / v)$ containing either $50 \mathrm{mM}$ FA or $25 \mathrm{mM}$ DEA or $50 \mathrm{mM}$ FA and $25 \mathrm{mM}$ DEA, respectively (Fig. 4).

Under basic conditions (in the presence of $25 \mathrm{mM}$ DEA), the amino groups of both the selector and the dipeptides are not protonated that is the double ionic interaction in the enantioselective zwitterionic process is no longer favored. Furthermore, due to repulsive interactions between the deprotonated carboxyl group of the dipeptide and the sulfonic acid group of the selector, the peptide eluted even before the dead-time and no enantioselectivity was observed.

Under acidic conditions (in the presence of $50 \mathrm{mM} \mathrm{FA}$ ), the quinuclidine moiety of the selector and the amino group of the peptides are protonated, while both the transaminocyclohexanesulfonic acid moiety of the selector and the carboxyl group of the analytes are partially protonated. In the present case, repulsive interactions between the positively charged selector and analyte facilitate the movement of the peptide through the column resulting in small retardation without enantioselectivity.

In the presence of both acid and base (the acid-to-base ratio being kept at 2:1), the presence of positive and negative charge in 


\section{ZWIX(+) $)^{\mathrm{TM}}$}
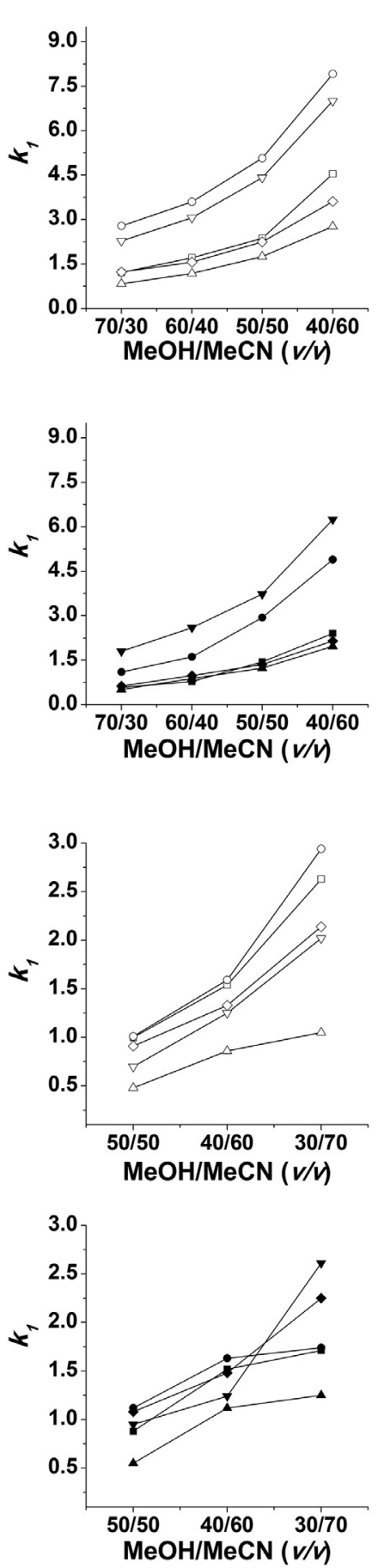
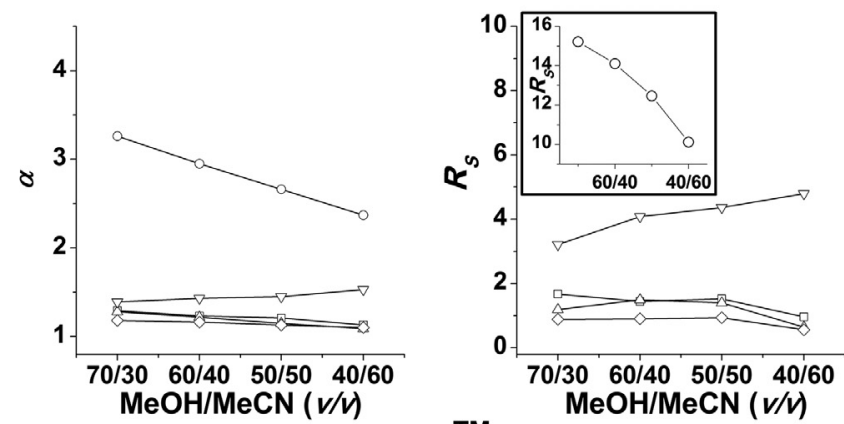

ZWIX(- $)^{\mathrm{TM}}$
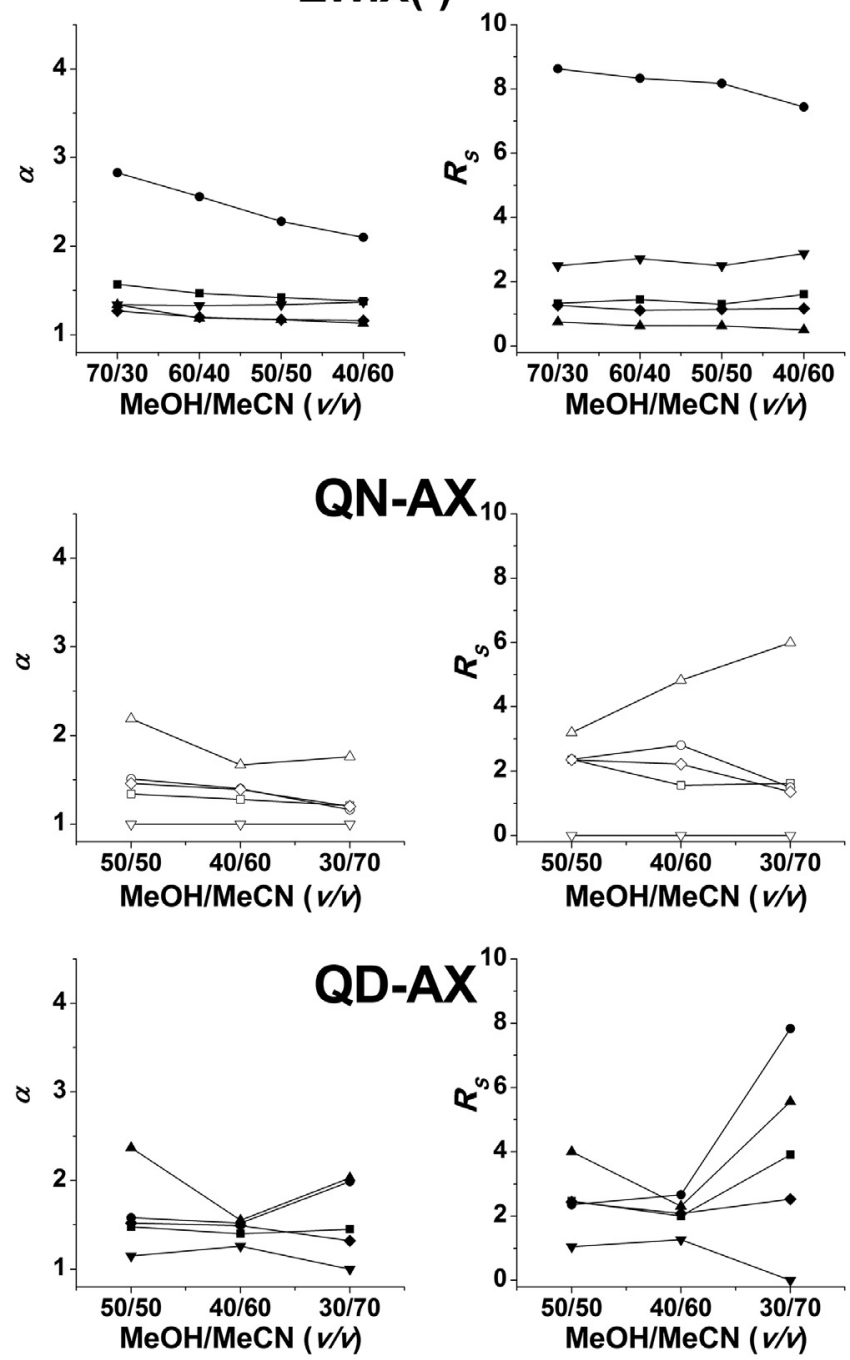
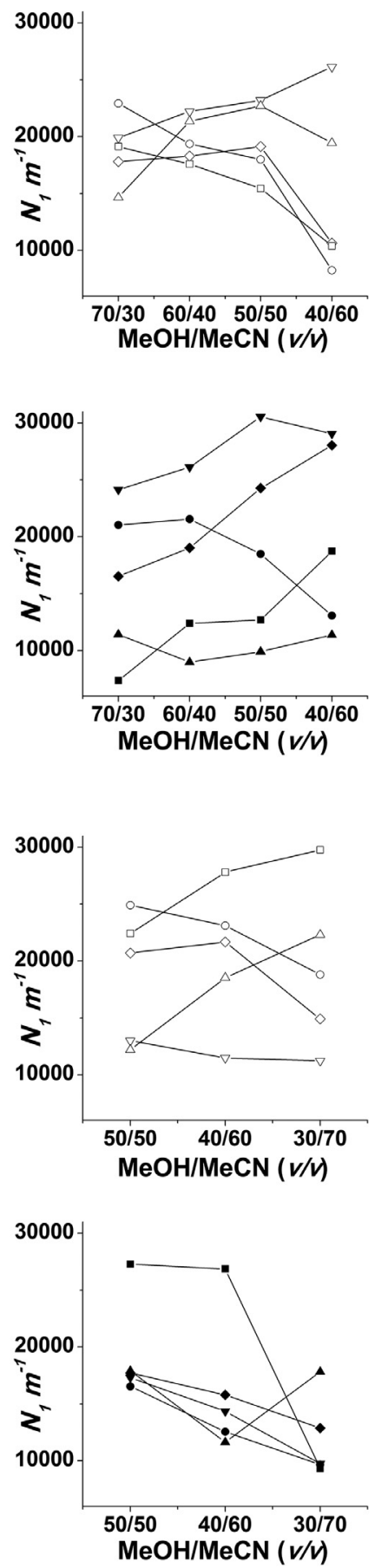

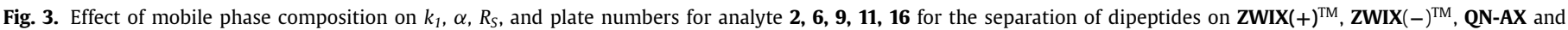

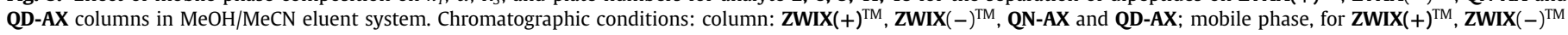

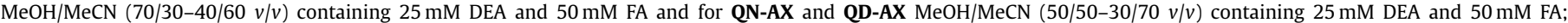

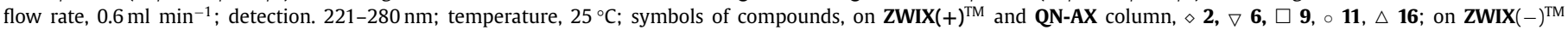
and QD-AX column, $\bullet \mathbf{2}, \mathbf{\nabla}, \mathbf{9}, \bullet \mathbf{1 1}, \triangle 16$.

both the selector and the dipeptide appears to favor double electrostatic interactions resulting in an enantioseparation (Fig. 4).

\subsection{Effect of the water content of the mobile phase}

On zwitterionic phases, the chromatographic performances can be tuned through variation of the organic components in non- aqueous $\mathrm{MeOH} / \mathrm{MeCN}$ mobile phases and through the addition of co- and counter-ions. Hydro-organic eluent conditions can also be utilized for the zwitterionic phases $[29,30]$. Hoffmann et al. [29] studied the effects of water addition to $\mathrm{MeOH}$ (up to $20 \mathrm{v} \%$ ) on the separation of acidic analytes on zwitterionic phases. With the addition of water, retention decreased and the mobile phase became eventually disadvantageous. Even a low percentage of wa- 
Table 2

Chromatographic data, retention factor $(k)$, separation factor $(\alpha)$, resolution $\left(R_{S}\right)$, elution sequences and plate numbers for the separation of dipeptides on ZWIX $(+)^{\mathrm{TM}}, \mathbf{Z W I X}(-)^{\mathrm{TM}}, \mathbf{Q N}-\mathbf{A X}$ and QD-AX columns in MeOH/MeCN mobile phase system.

\begin{tabular}{|c|c|c|c|c|c|c|c|c|c|c|c|c|}
\hline Compound & $k_{1}$ & $\alpha$ & Rs & $N_{1} m^{-1}$ & $N_{2} m^{-1}$ & E.O. & $k_{1}$ & $\alpha$ & Rs & $N_{1} m^{-1}$ & $N_{2} m^{-1}$ & E.O. \\
\hline \multicolumn{7}{|l|}{ ZWIX $(+)^{\mathrm{TM}}$} & \multicolumn{6}{|c|}{$\mathbf{Z W I X}(-)^{\mathrm{TM}}$} \\
\hline 1 & 2.60 & 1.03 & 0.29 & 12,067 & 6113 & $\mathrm{DD}<\mathrm{LL}$ & 1.30 & 1.35 & 1.24 & 7513 & 4793 & $\mathrm{LL}<\mathrm{DD}$ \\
\hline 1 & 2.13 & 1.14 & 0.97 & 10,847 & 5673 & $\mathrm{DL}<\mathrm{LD}$ & 1.26 & 1.03 & 0.21 & 5547 & 3407 & $\mathrm{LD}<\mathrm{DL}$ \\
\hline 2 & 2.25 & 1.13 & 0.94 & 19,140 & 14,880 & $\mathrm{DD}<\mathrm{LL}$ & 1.35 & 1.17 & 1.15 & 24,267 & 14,680 & $\mathrm{LL}<\mathrm{DD}$ \\
\hline 3 & 2.24 & 1.09 & 0.90 & 27,427 & 20,493 & $\mathrm{LL}<\mathrm{DD}$ & 1.31 & 1.00 & 0.00 & 21,787 & - & - \\
\hline 4 & 2.43 & 1.13 & 1.03 & 20,553 & 17,280 & $\mathrm{DD}<\mathrm{LL}$ & 1.79 & 1.12 & 0.80 & 17,413 & 12,220 & $\mathrm{LL}<\mathrm{DD}$ \\
\hline 4 & 1.91 & 1.12 & 0.53 & 13,813 & 10,760 & $\mathrm{DL}<\mathrm{LD}$ & 2.47 & 1.17 & 1.29 & 25,447 & 19,087 & $\mathrm{LD}<\mathrm{DL}$ \\
\hline 5 & 2.47 & 1.00 & 0.00 & 11,667 & - & - & 1.36 & 1.20 & 0.90 & 11,027 & 10,320 & $\mathrm{LL}<\mathrm{DD}$ \\
\hline 6 & 4.41 & 1.45 & 4.36 & 23,207 & 17,407 & $D<L$ & 3.73 & 1.34 & 2.50 & 30,560 & 13,133 & $L<D$ \\
\hline 7 & 0.10 & 1.00 & 0.00 & 6113 & - & - & 0.10 & 1.00 & 0.00 & 3880 & - & - \\
\hline 8 & 1.55 & 1.00 & 0.00 & 11,313 & - & - & 1.01 & 1.12 & 0.55 & 5433 & 4467 & $\mathrm{LL}<\mathrm{DD}$ \\
\hline 9 & 2.37 & 1.21 & 1.52 & 15,447 & 12,640 & $\mathrm{DD}<\mathrm{LL}$ & 1.44 & 1.42 & 1.30 & 12,680 & 10,320 & $\mathrm{LL}<\mathrm{DD}$ \\
\hline 10 & 2.64 & 1.28 & 1.96 & 8320 & 5607 & $\mathrm{DD}<\mathrm{LL}$ & 1.72 & 1.46 & 2.00 & 7380 & 6940 & $\mathrm{LL}<\mathrm{DD}$ \\
\hline 11 & 3.43 & 2.21 & 7.09 & 17,993 & 16,727 & $\mathrm{DD}<\mathrm{LL}$ & 1.73 & 1.96 & 3.50 & 23,807 & 21,987 & $\mathrm{LL}<\mathrm{DD}$ \\
\hline 12 & 3.16 & 1.00 & 0.00 & 6440 & - & - & 1.36 & 1.19 & 0.53 & 6673 & 5447 & $L<D$ \\
\hline 13 & 2.74 & 1.33 & 3.21 & 28,593 & 23,840 & $D<L$ & 2.37 & 1.26 & 2.00 & 16,560 & 16,367 & $L<D$ \\
\hline 14 & 2.90 & 1.55 & 2.55 & 12,347 & 11,487 & $\mathrm{DD}<\mathrm{LL}$ & 2.65 & 1.40 & 2.94 & 11,693 & 10,487 & $\mathrm{LL}<\mathrm{DD}$ \\
\hline 14 & 2.31 & 1.44 & 2.71 & 10,000 & 8987 & $\mathrm{DL}<\mathrm{LD}$ & 1.96 & 1.17 & 0.97 & 12,447 & 7500 & $\mathrm{LD}<\mathrm{DL}$ \\
\hline 15 & 1.86 & 1.28 & 1.95 & 14,760 & 12,473 & $\mathrm{DD}<\mathrm{LL}$ & 2.53 & 1.12 & 0.94 & 17,533 & 13,140 & $\mathrm{LL}<\mathrm{DD}$ \\
\hline 16 & 2.67 & 1.15 & 1.40 & 22,707 & 13,873 & $\mathrm{DD}<\mathrm{LL}$ & 1.23 & 1.17 & 0.63 & 9900 & 7920 & $\mathrm{LL}<\mathrm{DD}$ \\
\hline 16 & 1.50 & 1.24 & 1.77 & 12,140 & 7820 & $\mathrm{DL}<\mathrm{LD}$ & 0.72 & 1.16 & 0.53 & 13,280 & 6833 & $\mathrm{DL}<\mathrm{LD}$ \\
\hline \multicolumn{7}{|l|}{ QN-AX } & \multicolumn{6}{|c|}{ QD-AX } \\
\hline 1 & 0.60 & 1.00 & 0.00 & 11,220 & - & - & 0.60 & 1.75 & 1.07 & 23,560 & 16,907 & $\mathrm{LL}<\mathrm{DD}$ \\
\hline 1 & 0.49 & 1.00 & 0.00 & 6387 & - & - & 0.63 & 1.00 & 0.00 & 5413 & - & - \\
\hline 2 & 0.91 & 1.46 & 2.35 & 20,713 & 14,380 & $\mathrm{DD}<\mathrm{LL}$ & 1.08 & 1.52 & 2.44 & 17,727 & 14,593 & $\mathrm{LL}<\mathrm{DD}$ \\
\hline 3 & 0.25 & 1.00 & 0.00 & 2893 & - & - & 0.48 & 1.00 & 0.00 & 1940 & - & - \\
\hline 4 & 0.96 & 1.25 & 1.82 & 22,747 & 11,200 & $\mathrm{DD}<\mathrm{LL}$ & 0.96 & 1.40 & 2.43 & 28,087 & 19,500 & $\mathrm{LL}<\mathrm{DD}$ \\
\hline 4 & 0.76 & 1.00 & 0.00 & 3313 & - & - & 1.00 & 1.00 & 0.00 & 5240 & - & - \\
\hline 5 & 0.98 & 1.00 & 0.00 & 37,833 & - & - & 0.95 & 1.30 & 1.56 & 23,567 & 21,473 & $\mathrm{LL}<\mathrm{DD}$ \\
\hline 6 & 0.70 & 1.00 & 0.00 & 13,007 & - & - & 0.95 & 1.15 & 1.05 & 17,320 & 11,700 & $L<D$ \\
\hline 7 & * & - & - & 0 & - & - & $*$ & - & - & - & - & - \\
\hline 8 & * & - & - & 0 & - & - & $*$ & - & - & - & - & - \\
\hline 9 & 1.00 & 1.34 & 2.36 & 22,440 & 21,213 & $\mathrm{DD}<\mathrm{LL}$ & 0.88 & 1.48 & 2.47 & 27,293 & 25,473 & $\mathrm{LL}<\mathrm{DD}$ \\
\hline 10 & 1.26 & 1.25 & 1.88 & 30,800 & 30,393 & $\mathrm{DD}<\mathrm{LL}$ & 1.63 & 1.09 & 0.82 & 27,200 & 23,867 & $\mathrm{LL}<\mathrm{DD}$ \\
\hline 11 & 1.01 & 1.51 & 2.36 & 24,907 & 9940 & $\mathrm{DD}<\mathrm{LL}$ & 1.12 & 1.58 & 2.35 & 16,540 & 15,620 & $\mathrm{LL}<\mathrm{DD}$ \\
\hline 12 & 1.01 & 1.00 & 0.00 & 26,847 & - & - & 0.90 & 1.49 & 1.89 & 24,127 & 19,393 & $L<D$ \\
\hline 13 & 1.08 & 1.14 & 0.63 & 9393 & 8193 & $D<L$ & 0.93 & 1.28 & 1.52 & 10,140 & 7480 & $L<D$ \\
\hline 14 & 1.02 & 1.52 & 4.36 & 23,800 & 12,600 & $\mathrm{DD}<\mathrm{LL}$ & 0.99 & 2.01 & 4.73 & 20,467 & 9727 & $\mathrm{LL}<\mathrm{DD}$ \\
\hline 14 & 2.58 & 1.00 & 0.00 & 34,133 & - & - & 2.01 & 1.00 & 0.00 & 33,000 & - & - \\
\hline 15 & 0.41 & 1.00 & 0.00 & 23,507 & - & - & 0.54 & 1.71 & 2.14 & 30,480 & 24,520 & $\mathrm{LL}<\mathrm{DD}$ \\
\hline 16 & 0.48 & 2.19 & 3.20 & 12,187 & 10,147 & $\mathrm{DD}<\mathrm{LL}$ & 0.55 & 2.37 & 4.00 & 17,907 & 15,400 & $\mathrm{LL}<\mathrm{DD}$ \\
\hline 16 & 0.39 & 1.00 & 0.00 & 2753 & - & - & 0.54 & 1.00 & 0.00 & 2793 & - & - \\
\hline
\end{tabular}

Chromatographic conditions: column, ZWIX(+) ${ }^{\mathrm{TM}}$, ZWIX $(-)^{\mathrm{TM}}$, QN-AX and QD-AX; mobile phase, MeOH/MeCN (50/50 v/v) containing $25 \mathrm{mM}$ DEA and 50 mM FA flow rate, $0.6 \mathrm{ml} \mathrm{min}{ }^{-1}$; detection. $221-280 \mathrm{~nm}$; temperature, $25^{\circ} \mathrm{C}$; E.O. elution order; *eluted before $t_{0}$; $N_{1}, N_{2}$ values refers to $1.0 \mathrm{~m}$ column length.

ter $(<2 \%)$ shortened retention, but sometimes enhanced the resolution as observed by Zhang et al. [31] and Lajkó et al. [30]. Our finding with $2.0 \mathrm{v} \%$ water in the mobile phase $\left(\mathrm{MeOH} / \mathrm{MeCN} / \mathrm{H}_{2} \mathrm{O}\right.$ $49 / 49 / 2 v / v / v)$ containing $25 \mathrm{mM}$ DEA and $50 \mathrm{mM}$ FA is in accordance with this observation. Introducing water to a polarorganic mobile phase increases the solvation of polar compounds and the ionized sites leading to a decrease of retention. In other words, the increased solvation power of water strongly affects the strength of the electrostatic interactions, which fits to the retention mechanism based on ion-exchange processes. In the presence of $2.0 \mathrm{v} \%$ water, retention, in several cases, decreased slightly (especially on ZWIX(- $(-)^{\mathrm{TM}} \mathrm{CSP}$ ), while selectivity was not significantly influenced (Fig. S3). It should be noted, that in many cases water promotes the dissolution of the polar peptides in the injection solvent, which can become a critical issue in the analysis.

\subsection{Influence of the counter-ion}

Under PIM conditions for both anion- and cation-exchanger selectors, a predominant ion-exchange retention mechanism has been confirmed [32]. Retention can be regulated conveniently by variation of the counter-ion concentration through the competition of analytes and counter-ions for the ionic functional groups of the selector. The influence of counter-ions can be explained by a simple displacement model [33]. The plot of $\log k_{1} v s . \log c_{\text {counter-ion }}$ results in a linear relationship, where the slope of the straight line is proportional to the effective charge involved in the ionexchange process. In order to gain a deeper insight into the effects of counter-ion concentration on the retention mechanism, all four CSPs were studied in mobile phases $\mathrm{MeOH} / \mathrm{MeCN}(50 / 50 v / v)$ containing $12.5,25,50,100$ or $200 \mathrm{mM}$ FA and $6.25,12.5,25,50$ or $100 \mathrm{mM}$ DEA (the acid to base ratio was kept at 2:1) with analytes 2, 6, 9, 11, and 16 (Fig. 5). The data obtained with the four Cinchona alkaloid-based columns revealed that, in general, an increasing counter-ion concentration resulted in reduced retention factors as expected for an ion-exchanger. Under the studied conditions, the slopes, with a few exceptions, were practically invariant with regard to the structure of the dipeptide. However, in general, slightly more negative slopes were registered on anion-exchanger CSPs, indicating a difference between the zwitterionic and a "single ionic" CSP. This corroborates earlier findings of Hofmann et al. [34], Lajkó et al. [18,19], Grecsó et al. [28], and Ilisz et al. [35,36]. On all four CSPs, practically identical slopes were found for both enantiomers 

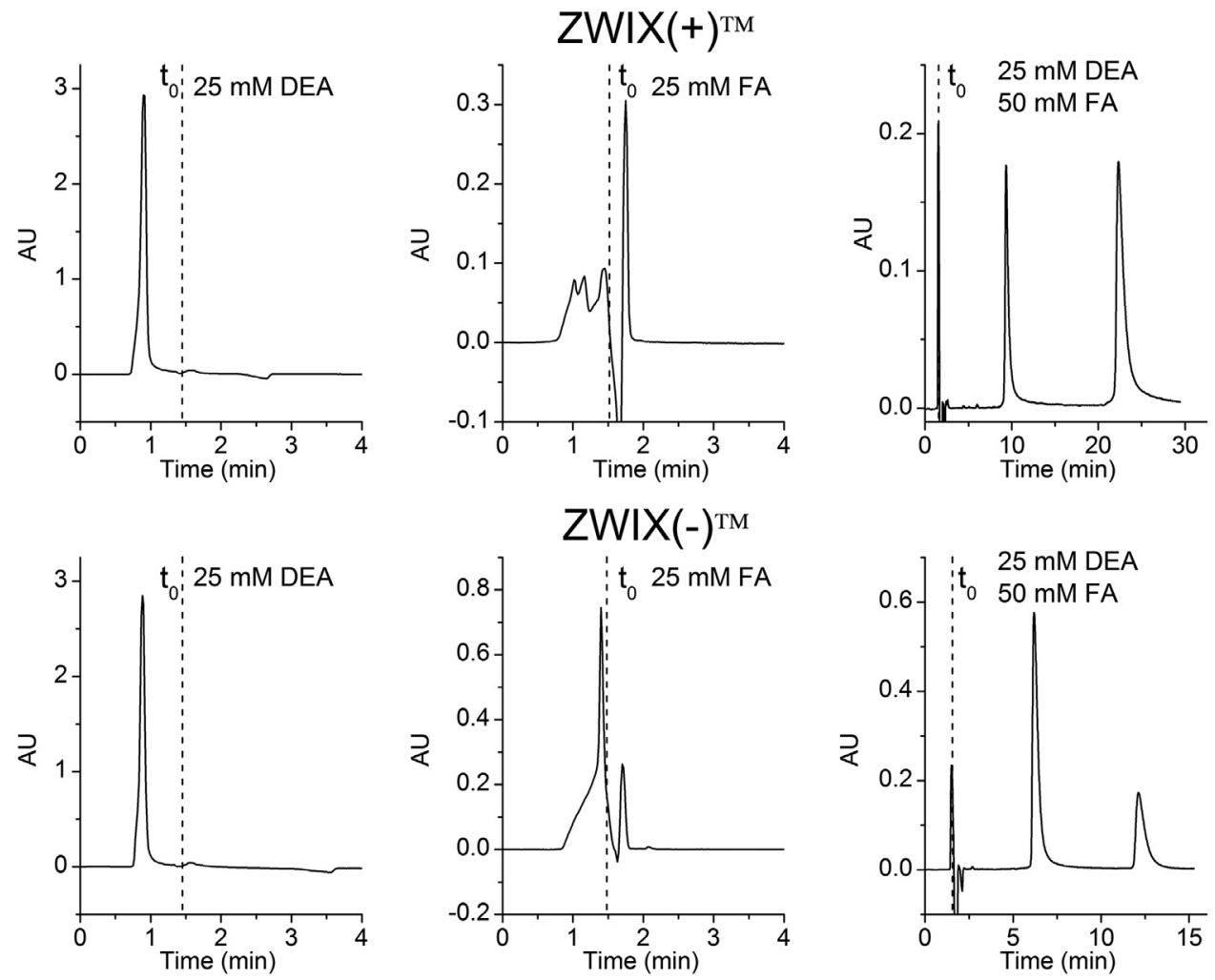

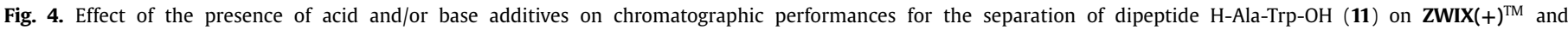

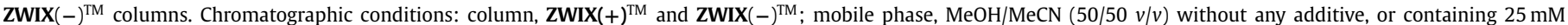
$\mathrm{DEA}$, or $25 \mathrm{mM}$ FA or $25 \mathrm{mM}$ DEA and $50 \mathrm{mM} \mathrm{FA}$, respectively; flow rate, $0.6 \mathrm{ml} \mathrm{min}^{-1}$; detection. $221-280 \mathrm{~nm}$; temperature, $25^{\circ} \mathrm{C}$.
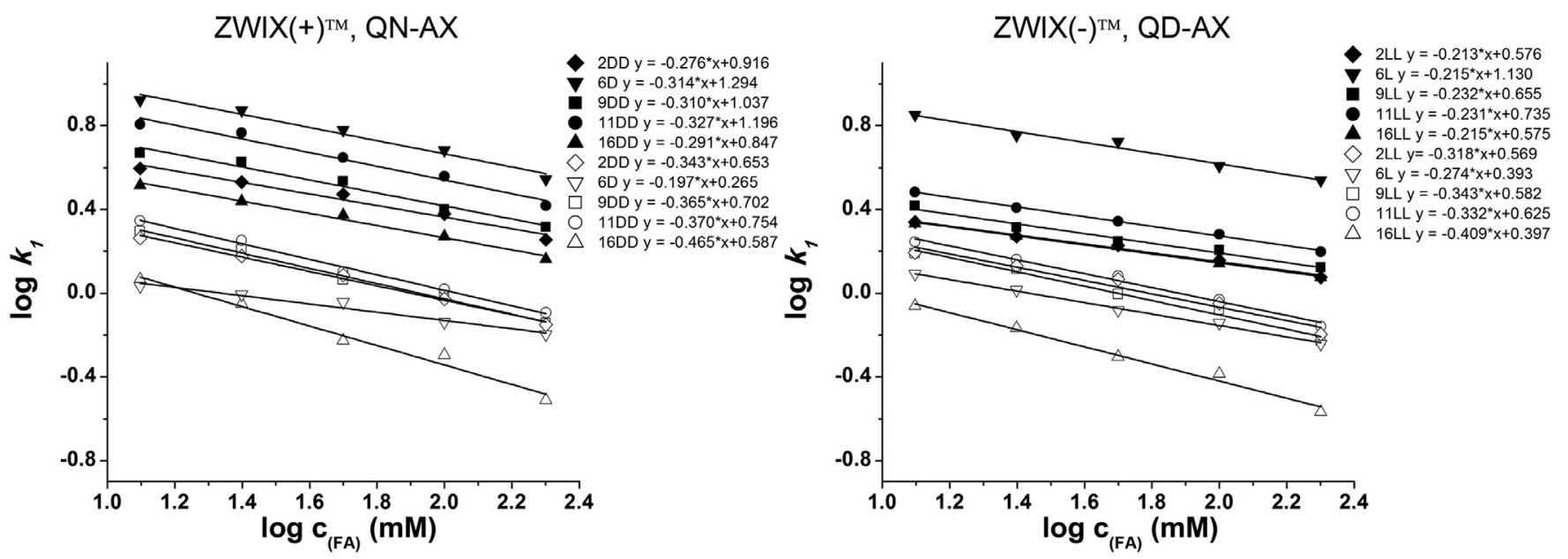

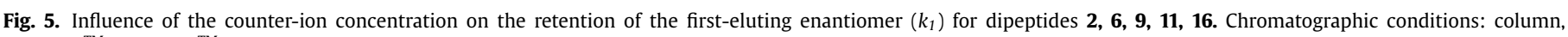

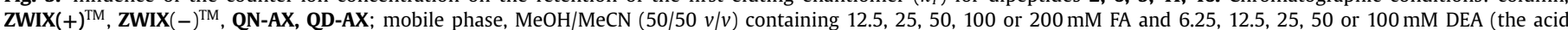

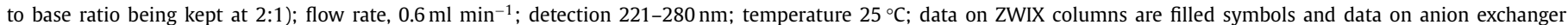
columns are empty symbols.

of a given peptide, i.e., the individual enantioselectivity characteristics remained constant when the counter-ion concentration was varied (data not shown). This means that at higher counter-ion concentrations dipeptides can be enantioseparated with lower retention times without significant loss of enantioselectivity.

\subsection{Structure-retention (selectivity) relationships}

The steric bulk and steric arrangement (configuration) of the amino acid at $\mathrm{N}$ - and the $\mathrm{C}$-terminus of the dipeptides will certainly affect in the association process with the selector moi- eties, thus influencing retention and stereoselective recognition. Table 2 and Table S1 summarize the $k_{1}, \alpha$, and $R_{S}$ values on ZWIX $(+)^{\mathrm{TM}}$, ZWIX $(-)^{\mathrm{TM}}$, QN-AX, QD-AX CSPs observed with mobile phases applied most frequently, i.e., $\mathrm{MeOH} / \mathrm{MeCN}(50 / 50 \mathrm{v} / \mathrm{v})$ (Table 2) and $\mathrm{MeOH} / \mathrm{THF}(70 / 30 \mathrm{v} / v$, Table S1) both containing $25 \mathrm{mM}$ DEA and $50 \mathrm{mM} F$.

The experimental results obtained with the same mobile phase under isocratic conditions allow the following considerations. Results are discussed on the basis of data obtained with $\mathrm{MeOH} / \mathrm{MeCN}$ mobile phases (Table 2). Similar tendencies could be registered with $\mathrm{MeOH} / \mathrm{THF}$ mobile phases (Table S1). 
(i) Of dipeptides 1, 4, 14, and 16, the homochiral (LL and DD) enantiomers show higher enantioselectivity (and, in most cases, also higher retention) than the heterochiral (LD and DL) stereoisomers.

(ii) The incorporation of a methylene group into the side chain of the amino acid, in most cases, affects both retention and selectivity. Comparison of analytes $\mathbf{2 ,} \mathbf{4}$, and $\mathbf{5}$ reveals that the presence of additional $\mathrm{CH}_{2}$ group(s) in $\mathbf{4}$ and $\mathbf{5}$ affects retention only slightly, but has a marked effect on enantioselectivity and resolution. The presence of homo-Phe (5) at the C-terminus resulted in lower $\alpha$ and $R_{S}$ values, while on quinine-based CSPs the full loss of enantiodiscrimination was observed. A similar trend was observed when the methylene group was inserted between the chiral center and the carboxyl group of the $C$ terminus ( 2 vs. 3). Free rotation of the carboxyl group around the bond with the methylene group probably affects a more distinct formation and fixation of the SO-SA complex and, consequently, peptides are retained but enantiodiscrimination is reduced or completely cancelled.

(iii) As expected, the esterification of $\mathrm{H}$-Ala-Phe-OH (4) to yield $\mathrm{H}$ Ala-Phe-OMe (7) resulted in the full loss of retardation and enantioselectivity especially on the anion-exchanger columns.

(iv) Amidated dipeptide H-Ala-Phe- $\mathrm{NH}_{2}$ (8) exhibited smaller retention and selectivity compared to H-Ala-Phe-OH (4) on zwitterionic phases, and a full loss of retardation and enantioselectivity on anion-exchanger phases was observed. The absence of the free carboxylic groups of $\mathbf{7}$ and $\mathbf{8}$ confirms the importance of the anion-exchanger site in analyte retention and the chiral recognition process.

(v) The incorporation of an achiral Gly-moiety into the dipeptide chain does not only reduce the number of possible stereoisomers, but also adds an increment of conformational flexibility due to the lack of a side chain [37]. Substitution of Ala-in $\mathbf{4}$ and 14 by Gly (12 and 13, respectively) generally resulted in slightly enhanced retention but in reduced enantioselectivity. The side chain in Ala-compared to Gly-supports the formation of an SO-SA complex and, consequently, affects chiral recognition. However, substitution at the $N$-terminus of Ala-by achiral $\beta$-Ala-in dipeptide 6 resulted in different behavior on zwitterionic phases (on anion-exchanger phases the same behavior was observed). All chromatographic parameters, $k_{1}, \alpha$ and $R_{S}$ exhibited higher values than analyte 4 .

(vi) Introducing a substituent into position 4 of the phenyl ring in $\mathbf{4}$, specifically, an $\mathrm{OH}$ group (compound 9) or a $\mathrm{NO}_{2}$ group (compound 10), resulted in drastic improvement in retention, selectivity, and resolution in most cases, especially on zwitterionic CSPs. The $\mathrm{OH}$ group of Tyr $(\mathbf{9})$ enables H-bond interactions, and the $p-\mathrm{NO}_{2}$ moiety of $\mathbf{1 0}$ with $\pi$-acidic character is capable of more pronounced $\pi-\pi$ interactions with the $\pi$-basic quinoline moiety of the selector, which significantly contributes to retention and chiral recognition.

(vii) The reversed sequence of Ala-and Phe-in peptides 4 and 14 greatly influenced the chromatographic behavior as well. The presence of an aromatic amino acid at the $\mathrm{N}$-terminus ensures higher retention and significantly better selectivity and resolution in all cases.

(viii) A further improvement in $k_{1}, \alpha$, and $R_{S}$ was seen in the case of H-Ala-Trp-OH (11), where the polar, aromatic side chain, in principle, could be capable of additional H-bond and $\pi-\pi$ interactions compared to $\mathrm{H}-\mathrm{Ala}-\mathrm{Phe}-\mathrm{OH}$. Thus, the highest $k_{1}, \alpha$, and $R_{S}$ values were found for H-Ala-Trp-OH.

Moreover, the structure of the selector significantly affected the chiral recognition of the investigated dipeptides. At the same eluent composition, $k_{1}$ values on the quinine-based $\mathrm{ZWIX}(+)^{\mathrm{TM}}$ were somewhat higher than those on the $\mathrm{ZWIX}(-)^{\mathrm{TM}} \mathrm{CSP}$, while the se- lectivity and resolution, especially in the case of dipeptides 1-11, were, in most cases, higher on the $\operatorname{ZWIX}(-)^{\mathrm{TM}}$ column. The same relationships were observed in the case of anion-exchanger QN-AX vs. QD-AX CSPs. It is worth noting that the zwitterionic dipeptide analytes are well retained on the QN/QD-AX anion-exchangers as well. In contrast, the positively charged $N$-terminus might rather be suspected to yield intermolecular electrostatic repulsion with the quinoline site of the SOs.

A comparison of the separation efficiency of zwitterionic $v s$. anion-exchanger CSPs at the same eluent composition revealed that the zwitterionic phases exhibited higher affinity for complex formation between the zwitterionic dipeptides and the SOs resulted in better selectivity and resolution values (the only exception was analyte 2). This phenomenon can be attributed to the double ion-pairing processes, probably in combination with hydrogen bonding.

The nature of bulk solvent components only slightly affects chiral discrimination. The presence of THF instead of $\mathrm{MeCN}$ in the mobile phase does not change enantioselectivity significantly. Both higher and lower $\alpha$ and $R_{S}$ values were registered and THF was less effective in the diastereoselective separation of $\mathbf{1 , 4}, \mathbf{1 4}$, and $\mathbf{1 6}$.

\subsection{Enantiomer elution order and enantio- and diastereoselectivity of the CSPS}

The quinine-based [ZWIX $\left.(+)^{\mathrm{TM}}, \mathrm{QN}-\mathrm{AX}\right]$ and quinidine-based [ZWIX $\left.(-)^{\mathrm{TM}}, \mathrm{QD}-\mathrm{AX}\right]$ chiral selectors are diastereomeric to each other (Fig. 1); in most cases, however, they behave like pseudoenantiomers [29]. As a consequence, upon changing from the quinine-based to the quinidine-based CSPs the elution order of the peptide enantiomers should be reversed. Due to the availability of enantiomerically pure standards the elution orders could be explored.

On the quinine-based $\mathrm{ZWIX}(+)^{\mathrm{TM}}$ and QN-AX CSPs, both the homochiral and the heterochiral peptide enantiomers with an amino acid with D-configuration at the $N$-terminus are less retained than the respective enantiomers with an $\mathrm{N}$-terminus amino acid with L-configuration. In contrast, on the quinidine-based ZWIX $(-)^{\mathrm{TM}}$ and QD-AX columns, the less retained enantiomers feature an amino acid with L-configuration. Exceptions were peptide $\mathbf{3}$ on $\mathrm{ZWIX}(+)^{\mathrm{TM}}$, the heterochiral analyte $\mathbf{1 6}$ on $\mathrm{ZWIX}(-)^{\mathrm{TM}}$ in $\mathrm{MeOH} / \mathrm{MeCN}$, and heterochiral 4 on QN-AX and QD-AX using $\mathrm{MeOH} / \mathrm{THF}$ mobile phase systems. The observed elution order does not change when changing $\mathrm{MeCN}$ to THF in the mobile phase (Table 2 and Table S1). It is interesting to note that the configuration of the amino acid at the $\mathrm{N}$-terminus controls the elution order employing zwitterionic or anion-exchanger CSPs. Under slightly acidic conditions, the $\mathrm{NH}_{2}$ group is positively charged. Thus, the primary ionic interaction on zwitterionic CSPs may occur between the positively charged $\mathrm{N}$-terminus of the amino acid and the negatively charged aminocyclohexanesulfonic acid moiety of the CSP. Since QN-AX and QD-AX CSPs do not possess a cation-exchanger site, the primary ionic interaction exists between the negatively charged carboxyl group at the $C$-terminus of the dipeptides and the positively charged quinuclidine moiety of the selector. Therefore, additional interactions need to be considered to interpret the observed enantioselectivity. The importance of $\mathrm{H}$-bond formations of the amide group (peptide bond) can be envisioned, but further studies will be needed to prove this assumption.

The diastereoselectivity of quinine- and quinidine-based selectors was investigated for the separation of the four diastereomers of dipeptides 1, 4, 14, and $\mathbf{1 6}$ (Fig. 6). Separations were carried out in $\mathrm{MeOH} / \mathrm{MeCN}$ and $\mathrm{MeOH} / \mathrm{THF}$ mobile phases at different ratios containing $25 \mathrm{mM}$ DEA and $50 \mathrm{mM}$ FA. Separation of the four peptide stereoisomers was successful in $\mathrm{MeOH} / \mathrm{MeCN}(50 / 50$ $v / v)$ mobile phase on $\operatorname{ZWIX}(+)^{\mathrm{TM}}$ in the case of $\mathbf{1}, \mathbf{1 4}$, and $\mathbf{1 6}$ 

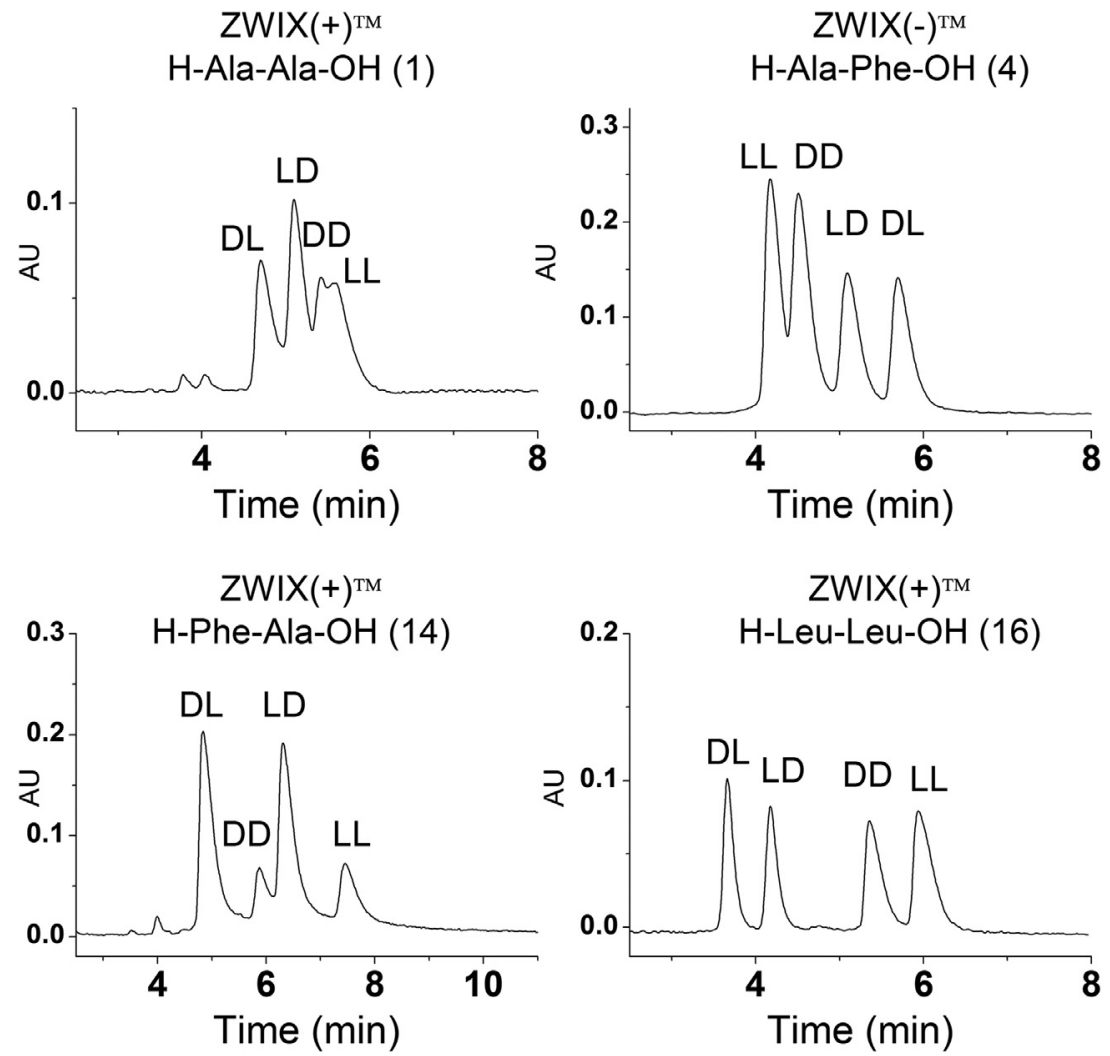

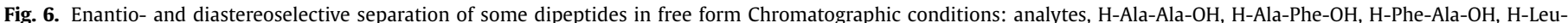

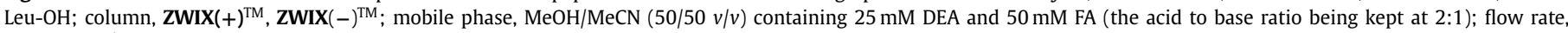
$0.6 \mathrm{ml} \mathrm{min}{ }^{-1}$; detection $221-280 \mathrm{~nm}$; temperature $25^{\circ} \mathrm{C}$.

and on ZWIX $(-)^{\mathrm{TM}}$ for $\mathbf{1 , 4}$, 14. The MeOH/THF (70/30 $\left.v / v\right)$ mobile phase system worked successfully on ZWIX $(+)^{\mathrm{TM}}$ for 1, 14, 16 and on ZWIX $(-)^{\mathrm{TM}}$ for 16. The anion-exchanger QN-AX and QDAX columns exhibited only low diastereoselectivity, and separation of the four stereoisomers could not be achieved. Selected chromatograms are depicted in Fig. 6.

\subsection{Effect of temperature and thermodynamic parameters}

Stereoselective interactions are greatly affected by the temperature in chiral separations. Therefore, the column temperature is often optimized and kept well controlled [38-41]. The difference in the change in standard enthalpy $\Delta\left(\Delta \mathrm{H}^{\circ}\right)$ and entropy $\Delta\left(\Delta \mathrm{S}^{\circ}\right)$ for enantiomers in chiral separations can be obtained from the van't Hoff equation:

$\ln \alpha=-\frac{\Delta\left(\Delta H^{\circ}\right)}{R T}+\frac{\Delta\left(\Delta S^{\circ}\right)}{R}$

where $R$ is the universal gas constant, $T$ is temperature in Kelvin, and $\alpha$ is the apparent selectivity factor. Theoretically, retentions on a chiral CSP are composed of achiral and chiral contributions, which may vary in their magnitude; however, in the present study, these two components are not differentiated $[40,41]$.

In order to investigate the effects of temperature on the chromatographic parameters, a variable temperature study was carried out for dipeptides 2, 6, 9, 11, and 16 on $\mathrm{ZWIX}(+)^{\mathrm{TM}}, \mathrm{ZWIX}(-)^{\mathrm{TM}}$, $\mathrm{QN}-\mathrm{AX}$, and $\mathrm{QD}-\mathrm{AX}$ columns in the temperature range $5-50{ }^{\circ} \mathrm{C}$ (at 5 or $10{ }^{\circ} \mathrm{C}$ increments) in mobile phases based on $\mathrm{MeOH} / \mathrm{MeCN}$ $(50 / 50 v / v)$ and $\mathrm{MeOH} / \mathrm{THF}(70 / 30 v / v)$ both containing $50 \mathrm{mM} \mathrm{FA}$ and $25 \mathrm{mM}$ DEA. The experimental data are summarized in Table $\mathrm{S} 2$.

On the four columns with both mobile phase systems, the retention decreased with increasing temperature. It is evident that an increase in the separation temperature generally lowers the separation factor. For the investigated dipeptides this behavior was seen in all cases, i.e., $k$ and $\alpha$ decreased with increasing temperature. From the chromatographic data van't Hoff plots were constructed and, as a general trend, the selectivity $(\ln \alpha v$ s. 1/T) gave clearly linear van't Hoff plots, as indicated by the correlation coefficients listed in Tables $3 \mathrm{a}$ and $3 \mathrm{~b}$. The $\Delta\left(\Delta H^{\circ}\right)$ and $\Delta\left(\Delta S^{\circ}\right)$ values in both $\mathrm{MeOH} / \mathrm{MeCN}$ and $\mathrm{MeOH} / \mathrm{THF}$ mobile phases were, in most cases, slightly higher compared to those found on $\mathrm{ZWIX}(-)^{\mathrm{TM}}$ and $\mathrm{ZWIX}(+)^{\mathrm{TM}}$ as well as QD-AX and QN-AX. (Most exceptions were observed for QD-AX in the $\mathrm{MeOH} / \mathrm{MeCN}$ mobile phase, see Tables $3 \mathrm{a}$ and $3 \mathrm{~b})$. Regarding the $\Delta\left(\Delta G^{\circ}\right)_{298 \mathrm{~K}}$ values, these were the highest in the case of ZWIX phases for the dipeptide H-AlaTrp-OH (11), while on anion-exchanger columns, the highest values were found for $\mathrm{H}$-Leu-Leu-OH (16). A comparison of the $Q$ values (defined as $\Delta\left(\Delta H^{\circ}\right) /\left[298 \times \Delta\left(\Delta S^{\circ}\right)\right]$ on different CSPs and mobile phase systems revealed that $Q$ values were higher than 1.0 in all cases, indicating the relatively high contribution of the enthalpy to the free energy, i.e., enantiodiscrimination was enthalpically driven.

\section{Conclusions}

Stereoisomeric dipeptides were separated on Chiralpak $\mathrm{ZWIX}(+)^{\mathrm{TM}}$ and ZWIX $(-)^{\mathrm{TM}}$ as zwitterionic-based, and QN-AX and QD-AX as anion-exchanger-based CSPs in polar-ionic mode. Separations were accomplished and the chromatographic retention behavior could be tuned by the variation of mobile phase components. The application of $\mathrm{MeOH}$ and $\mathrm{MeCN}$ solvent combinations with acid and base additives ensures easy variability of the separations through the influence on electrostatic, $\pi-\pi$, and $\mathrm{H}$-bond interactions. Applying $\mathrm{MeOH} / \mathrm{THF}$ as bulk solvent instead of $\mathrm{MeOH} / \mathrm{MeCN}$ resulted in an improvement in enantioselectivity 
Table 3a

Thermodynamic parameters, $\Delta\left(\Delta H^{\mathrm{o}}\right), \Delta\left(\Delta S^{\mathrm{o}}\right)$, Tx $\Delta\left(\Delta S^{\mathrm{o}}\right), \Delta\left(\Delta G^{\mathrm{o}}\right)$, correlation coefficients $\left(R^{2}\right)$ and $Q$ values of dipeptides on ZWIX $(+)^{\mathrm{TM}}$, ZWIX $(-)^{\mathrm{TM}}$ columns.

\begin{tabular}{|c|c|c|c|c|c|c|c|}
\hline Analyte & Mobile phase & $-\Delta\left(\Delta H^{\circ}\right)(\mathrm{kJ} / \mathrm{mol})$ & $-\Delta\left(\Delta S^{\circ}\right)\left(\mathrm{J} /\left(\mathrm{mol}^{*} \mathrm{~K}\right)\right.$ & Correlation coefficients $\left(R^{2}\right)$ & $-\mathrm{T} x \Delta\left(\Delta S^{\circ}\right)_{298 \mathrm{~K}}(\mathrm{~kJ} / \mathrm{mol})$ & $-\Delta\left(\Delta G^{\circ}\right)_{298 \mathrm{~K}}(\mathrm{~kJ} / \mathrm{mol})$ & $Q$ \\
\hline \multicolumn{8}{|l|}{$\mathrm{ZWIX}(+)^{\mathrm{TM}}$} \\
\hline 2LL,2DD & $\mathbf{a}$ & 0.6 & 1.1 & 0.9947 & 0.3 & 0.3 & 1.8 \\
\hline $6 \mathrm{~L}, 6 \mathrm{D}$ & & 2.6 & 5.7 & 0.9979 & 1.7 & 0.9 & 1.5 \\
\hline 9LL,9DD & & 1.1 & 2.0 & 0.9927 & 0.6 & 0.5 & 1.8 \\
\hline 11LL,11DD & & 5.4 & 11.7 & 0.9997 & 3.5 & 1.9 & 1.5 \\
\hline 16LL,16DD & & 0.6 & 0.7 & 0.9603 & 0.2 & 0.4 & 2.9 \\
\hline \multicolumn{8}{|l|}{$\operatorname{ZWIX}(+)^{\mathrm{TM}}$} \\
\hline 2LL,2DD & b & 1.3 & 3.1 & 0.9989 & 0.9 & 0.4 & 1.4 \\
\hline $6 \mathrm{~L}, 6 \mathrm{D}$ & & 3.2 & 7.8 & 0.9979 & 2.3 & 0.9 & 1.4 \\
\hline 9LL,9DD & & 1.8 & 3.6 & 0.9858 & 1.1 & 0.7 & 1.7 \\
\hline 11LL,11DD & & 6.0 & 11.9 & 0.9898 & 3.5 & 2.5 & 1.7 \\
\hline 16LL,16DD & & 1.7 & 2.9 & 0.9811 & 0.9 & 0.8 & 2.0 \\
\hline \multicolumn{8}{|l|}{$\operatorname{ZWIX}(-)^{\mathrm{TM}}$} \\
\hline 2LL,2DD & $\mathbf{a}$ & 1.6 & 3.7 & 0.9912 & 1.1 & 0.5 & 1.5 \\
\hline $6 \mathrm{~L}, 6 \mathrm{D}$ & & 2.0 & 3.6 & 0.9987 & 1.1 & 0.9 & 1.9 \\
\hline 9LL,9DD & & 2.5 & 5.4 & 0.9932 & 1.6 & 0.9 & 1.6 \\
\hline 11LL,11DD & & 4.3 & 8.8 & 0.9969 & 2.6 & 1.7 & 1.6 \\
\hline 16LL,16DD & & 0.9 & 1.6 & 0.9902 & 0.5 & 0.4 & 1.9 \\
\hline \multicolumn{8}{|l|}{ ZWIX $(-)^{\mathrm{TM}}$} \\
\hline 2LL,2DD & b & 2.7 & 6.5 & 0.9991 & 1.9 & 0.8 & 1.4 \\
\hline $6 \mathrm{~L}, 6 \mathrm{D}$ & & 3.1 & 7.0 & 0.9990 & 2.1 & 1.0 & 1.5 \\
\hline 9LL,9DD & & 3.6 & 7.9 & 0.9938 & 2.4 & 1.2 & 1.5 \\
\hline 11LL,11DD & & 5.8 & 12.0 & 0.9961 & 3.6 & 2.2 & 1.6 \\
\hline 16LL,16DD & & 2.4 & 4.8 & 0.9908 & 1.4 & 1.0 & 1.7 \\
\hline
\end{tabular}

Chromatographic conditions: columns, ZWIX $(+)^{\mathrm{TM}}$ and ZWIX(- $)^{\mathrm{TM}}$; mobile phase, a, MeOH/MeCN $(50 / 50 v / v)$ containing $50 \mathrm{mM}$ FA and $25 \mathrm{mM} \mathrm{DEA}, \mathbf{b}, \mathrm{MeOH} / \mathrm{THF}(70 / 30$

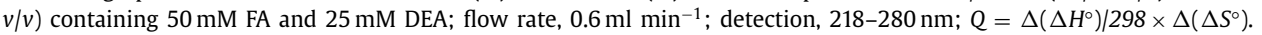

Table 3b

Thermodynamic parameters, $\Delta\left(\Delta H^{\circ}\right), \Delta\left(\Delta S^{\circ}\right), \operatorname{Tx} \Delta\left(\Delta S^{\circ}\right), \Delta\left(\Delta G^{\circ}\right)$, correlation coefficients $\left(R^{2}\right)$ and $Q$ values of dipeptides on QN-AX and QD-AX columns.

\begin{tabular}{|c|c|c|c|c|c|c|c|}
\hline Analyte & Mobile phase & $-\Delta\left(\Delta H^{\circ}\right)(\mathrm{kJ} / \mathrm{mol})$ & $-\Delta\left(\Delta S^{\circ}\right)\left(\mathrm{J} /\left(\mathrm{mol}^{*} \mathrm{~K}\right)\right.$ & Correlation coefficients $\left(R^{2}\right)$ & $-\mathrm{T} x \Delta\left(\Delta S^{\circ}\right)_{298 \mathrm{~K}}(\mathrm{~kJ} / \mathrm{mol})$ & $-\Delta\left(\Delta G^{0}\right)_{298 \mathrm{~K}}(\mathrm{~kJ} / \mathrm{mol})$ & $Q$ \\
\hline \multicolumn{8}{|l|}{ QN-AX } \\
\hline 2LL,2DD & $\mathbf{a}$ & 2.9 & 6.6 & 0.9594 & 2.0 & 0.9 & 1.5 \\
\hline a $6 \mathrm{~L}, 6 \mathrm{D}$ & & 3.6 & 6.8 & 0.9968 & 2.0 & 1.6 & 1.8 \\
\hline 9LL,9DD & & 7.2 & 22.1 & 0.9693 & 6.6 & 0.6 & 1.1 \\
\hline 11LL,11DD & & 7.1 & 20.7 & 0.9883 & 6.2 & 0.9 & 1.1 \\
\hline 16LL,16DD & & 14.6 & 42.9 & 0.9785 & 12.8 & 1.8 & 1.1 \\
\hline \multicolumn{8}{|l|}{ QN-AX } \\
\hline 2LL,2DD & b & 3.0 & 6.2 & 0.9812 & 1.8 & 1.2 & 1.7 \\
\hline${ }^{\mathrm{b}} 6 \mathrm{~L}, 6 \mathrm{D}$ & & 2.9 & 8.6 & 0.9889 & 2.6 & 0.3 & 1.1 \\
\hline 9LL,9DD & & 6.4 & 17.5 & 0.9897 & 5.2 & 1.2 & 1.2 \\
\hline 11LL,11DD & & 8.9 & 24.3 & 0.9918 & 7.2 & 1.7 & 1.2 \\
\hline 16LL,16DD & & 9.6 & 23.9 & 0.9835 & 7.1 & 2.5 & 1.4 \\
\hline \multicolumn{8}{|l|}{ QD-AX } \\
\hline 2LL,2DD & $\mathbf{a}$ & 4.9 & 13.0 & 0.9976 & 3.9 & 1.0 & 1.3 \\
\hline $6 \mathrm{~L}, 6 \mathrm{D}$ & & 2.1 & 5.6 & 0.9949 & 1.7 & 0.4 & 1.2 \\
\hline 9LL,9DD & & 4.2 & 10.9 & 0.9914 & 3.2 & 1.0 & 1.3 \\
\hline 11LL,11DD & & 6.5 & 17.8 & 0.9935 & 5.3 & 1.2 & 1.2 \\
\hline 16LL,16DD & & 7.8 & 18.0 & 0.9942 & 5.3 & 2.5 & 1.5 \\
\hline \multicolumn{8}{|l|}{ QD-AX } \\
\hline 2LL,2DD & $\mathbf{b}$ & 3.7 & 8.1 & 0.9962 & 2.4 & 1.3 & 1.5 \\
\hline $6 \mathrm{~L}, 6 \mathrm{D}$ & & 2.7 & 7.0 & 0.9918 & 2.1 & 0.6 & 1.3 \\
\hline 9LL,9DD & & 8.9 & 25.5 & 0.9942 & 7.6 & 1.3 & 1.2 \\
\hline 11LL,11DD & & 10.6 & 30.3 & 0.9970 & 9.0 & 1.6 & 1.2 \\
\hline 16LL,16DD & & 15.2 & 41.2 & 0.9923 & 12.3 & 2.9 & 1.2 \\
\hline
\end{tabular}

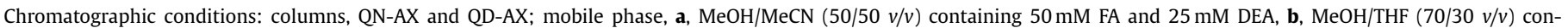
taining $50 \mathrm{mM}$ FA and $25 \mathrm{mM}$ DEA; flow rate, $0.6 \mathrm{ml} \mathrm{min}^{-1}$; detection, 218 - $280 \mathrm{~nm}$; temperature range,

a $5-20^{\circ} \mathrm{C}$.

b $5-30{ }^{\circ} \mathrm{C} ; \mathrm{Q}=\Delta\left(\Delta H^{\circ}\right) / 298 \times \Delta\left(\Delta S^{\circ}\right)$.

and resolution in some cases. To shed light on the enantiodiscrimination process, the influence of analyte structures on the chromatographic performance was studied. Enhanced rotation ability of the dipeptides (substitution of Ala-by Gly-or $\beta$-Ala) hindering the formation and fixation of the more distinct SO-SA complex leads to lower enantioselectivity. Homochiral dipeptides displayed higher enantioselectivity than their heterochiral counterparts, indicating the importance of the configuration with respect to the chiral recognition process. Esterification or ami- dation of the C-terminal carboxyl group brought about a drastic loss of enantioselectivity observed on the Cinchona alkaloid-based CSPs. Enhancement in the $\pi$-acidic character of the analytes enabled more pronounced $\pi-\pi$ interactions with the $\pi$-basic quinoline moiety of selector, providing enhanced retention and chiral recognition. The elution sequence, with a few exceptions, was found to be reversed upon changing from QN-based CSPs to QD-based CSPs. This offers the possibility to determine the enantiomeric excess of compounds, because elution of the minor enan- 
tiomer before the major one is preferable in order to avoid peak orverlapping.

\section{Declaration of Competing Interest}

\section{Authors declare no conflict of interest.}

\section{Acknowledgements}

This work was supported by the National Research, Development and Innovation Office, project grant GINOP-2.3.2-15-201600034. The Ministry of Human Capacities, Hungary grant 20391$3 / 2018 / F E K U S T R A T$ is also acknowledged. The authors highly acknowledge Pilar Franco (Chiral Technologies Europe) for providing the chiral columns.

\section{Supplementary material}

Supplementary material associated with this article can be found, in the online version, at doi:10.1016/j.chroma.2019.460574.

\section{References}

[1] M.C. Manning, K. Patel, R.T. Borchard, Stability of protein pharmaceuticals, Pharm. Res. 6 (1989) 903-918, doi:10.1023/A:1015929109894.

[2] S. Ritz-Timme, M.J. Collins, Racemization of aspartic acid in human proteins, Ageing Res. Rev. 1 (2002) 43-59, doi:10.1016/S0047-6374(01)00363-3.

[3] T. Uchiyama, A. Kotani, T. Kishida, H. Tatsumi, A. Okamoto, T. Fujita, M. Murakami, S. Muranishi, A. Yamamoto, Effects of various protease inhibitors on the stability and permeability of [D-Ala2, D-Leu5]enkephalin in the rat intestine: comparison with leucine encephalin, J. Pharm. Sci. 87 (1998) 448-452, doi: $10.1021 / \mathrm{js} 970357+$

[4] K. Fujita, H. Minakata, K. Nomoto, Y. Furukawa, M. Kobayashi, Structure-activity relations of fulicin, a peptide containing a D-amino acid residue, Peptides 16 (1995) 565-568, doi:10.1016/0196-9781(95)00022-C.

[5] H. Gerhard, A. Sievers-Engler, G. Jahanshah, Z. Pataj, F. Ianni, H. Gross, W. Lindner, M. Lämmerhofer, Methods for the comprehensive structural elucidation of constitution and stereochemistry of lipopeptides, J. Chromatogr. A 1428 (2016) 280-291, doi:10.1016/j.chroma.2015.05.065.

[6] B. Natalini, R. Sardella, F. Ianni, Enantioseparation by high-performance liquid chromatography based on chiral ligand exchange, in: G.K.E. Scriba (Ed.), Chiral Separations, Humana Press, New York, 2013, pp. 191-208, doi:10.1007| 978-1-62703-263-6_11.

[7] M.H. Hyun, Enantioseparation of primary amino compounds by highperformance liquid chromatography using chiral crown-based chiral stationary phase, in: G.K.E. Scriba (Ed.), Chiral Separations, Humana Press, New York, 2013, pp. 165-176, doi:10.1007/978-1-62703-263-6_9.

[8] J. Zukowski, M. Pawlowska, M. Nagatkina, D.W. Armstrong, High-performance liquid chromatographic enantioseparation of glycyl di- and tripeptides on native cyclodextrin bonded phases: mechanistic considerations, J. Chromatogr. A 629 (1993) 169-179, doi:10.1016/0021-9673(93)87032-H.

[9] Y. Tang, J. Zukowski, D.W. Armstrong, Investigation on enantiomeric separations of fluorenylmethoxycarbonyl amino acids and peptides by highperformance liquid chromatography using native cyclodextrins as chiral stationary phases, J. Chromatogr. A 743 (1996) 261-271, doi:10.1016/ 0021-9673(96)00302-0.

[10] D.W. Armstrong, Y. Tang, S. Chen, Y. Zhou, C. Bagwill, J.R. Chen, Macrocyclic antibiotics as a new class of chiral selectors for liquid chromatography, Anal. Chem. 66 (1994) 1473-1484, doi:10.1021/ac00081a019.

[11] A. Berthod, X. Chen, J.P. Kullman, D.W. Armstrong, F. Gasparrini, I. D’Acquarica, C. Villani, A. Carotti, Role of the carbohydrate moieties in chiral recognition on teicoplanin-based LC stationary phases, Anal. Chem. 72 (2000) 1767-1780, doi:10.1021/ac991004t.

[12] I. Ilisz, R. Berkecz, A. Péter, High-performance liquid chromatographic separation of amino acid enantiomers and small peptides on macrocyclic-based chiral stationary phases: a review, J. Sep. Sci. 29 (2006) 1305-1321, doi:10.1002/ jssc.200600046.

[13] I. Ilisz, A. Aranyi, Z. Pataj, A. Péter, Enantioseparations by high-performance liquid chromatography using macrocyclic glycopeptide-based chiral stationary phases: an overview, in: G.K.E. Scriba (Ed.), Chiral Separation, Methods and Protocols, Humana Press, Springer, New York, 2013, pp. 137-163, doi:10.1007/ 978-1-62703-263-6_8.

[14] K.H. Ekborg-Ott, D.W.Armstrong Y.Liu, Highly enantioselective HPLC separations using the covalently bonded macrocyclic antibiotic, ristocetin a chiral stationary phase, Chirality 10 (1998) 434-483, doi:10.1002/(SICI)1520-636X(1998) 10:5〈434::AID-CHIR10) 3.0.CO;2-0.

[15] Y. Shu, J.C. Lang, Z.S. Breitbach, H. Qui, J. Smuts, M. Kiyono-Shimobe, M. Yasuda, D.W. Armstrong, Separation of therapeutic peptides with cyclofructan and glycopeptide based columns in hydrophilic interaction liquid chromatography, J. Chromatogr. A 1390 (2015) 50-61, doi:10.1016/j.chroma.2015.02.018.
[16] R.M. Wimalasinghe, Z.S. Breitbach, J.T. Lee, D.W. Armstrong, Separation of peptides on superficially porous particle based macrocyclic glycopeptide liquid chromatography stationary phases: consideration of fast separation, Anal. Bioanal. Chem. 409 (2017) 2437-2447, doi:10.1007/s00216-0170190-4.

[17] C.V. Hoffmann, R. Pell, M. Lämmerhofer, W. Lindner, Synergistic effects on enantioselectivity of zwitterionic chiral stationary phases for separation of chiral acids, bases and amino acids by HPLC, Anal. Chem. 80 (2008) 8780-8789, doi:10.1021/ac801384f.

[18] G. Lajkó, N. Grecsó, G. Tóth, F. Fülöp, W. Lindner, A. Péter, I. Ilisz, A comparative study of enantioseparations of $n^{\alpha}$-Fmoc proteinogenic amino acids on quinine-based zwitterionic and anion exchanger-type chiral stationary phases under hydro-organic liquid and subcritical fluid chromatographic conditions, Molecules 21 (2016) 1579-1598, doi:10.3390/molecules21111579.

[19] G. Lajkó, N. Grecsó, G. Tóth, F. Fülöp, W. Lindner, I. Ilisz, Antal Péter, Liquid and subcritical fluid chromatographic enantioseparation of $n^{\alpha}$-Fmoc protein amino acids on quinidine-based zwitterionic and anion exchanger type chiral stationary phases. a comparative study, Chirality 29 (2017) 225-238, doi:10.1002/chir.22700.

[20] S. Wernisch, W. Lindner, Versatility of Cinchona-based zwitterionic chiral stationary phases: enantiomer and diastereomer separations of nonprotected oligopeptides utilizing a multi-modal chiral recognition mechanism, J. Chromatogr. A 1269 (2012) 297-307, doi:10.1016/j.chroma.2012.06. 094.

[21] M. Lämmerhofer, Liquid chromatographic enantiomer separation with special focus on zwitterionic chiral ion-exchangers, Anal. Bioanal. Chem. 406 (2014) 6095-6103, doi:10.1007/s00216-014-7930-5.

[22] I. Ilisz, A. Aranyi, Z. Pataj, A. Péter, Recent advances in the enantioseparation of amino acids and related compounds: a review, J. Pharm. Biomed. Anal. 69 (2012) 28-41, doi:10.1016/j.jpba.2012.01.020.

[23] I. Ilisz, Z. Gecse, Z. Pataj, F. Fülöp, G. Tóth, W. Lindner, A. Péter, Direct highperformance liquid chromatographic enantioseparation of secondary amino acids on Cinchona alkaloid-based chiral zwitterionic stationary phases. unusual temperature behavior, J. Chromatogr. A 1363 (2014) 169-177, doi:10.1016/j. chroma.2014.06.087.

[24] I. Ilisz, A. Péter, W. Lindner, State-of-the-art enantioseparations of natural and unnatural amino acids by high-performance liquid chromatography, TrAC Trends Anal. Chem. 81 (2016) 11-22, doi:10.1016/j.trac.2016.01.016.

[25] G.B. Fields, Methods in Enzymology, Volume 289 Solid-Phase Peptide Synthesis, 1st ed., Academic Press, 1997.

[26] M. Bodanszky, A. Bodanszky, in: The Practice of Peptide Synthesis, 2nd Ed. Springer, Berlin, 1994, p. 110, doi:10.1007/978-3-642-85055-4

[27] N. Grecsó, M. Kohout, A. Carotti, R. Sardella, B. Natalini, F. Fülöp, W. Lindner, A. Péter, I. Ilisz, Mechanistic considerations of enantiorecognition on novel Cinchona alkaloid-based zwitterionic chiral stationary phases from the aspect of the separation of trans-paroxetine enantiomers as model compounds, J. Pharm. Biomed. Anal. 124 (2016) 164-173, doi:10.1016/j.jpba.2016.02.043.

[28] N. Grecsó, E. Forró, F. Fülöp, A. Péter, I. Ilisz, W. Lindner, Combinatorial effects of the configuration of the cationic and the anionic chiral subunits of four zwitterionic chiral stationary phases leading to reversal of elution order of cyclic $\beta^{3}$-amino acid enantiomers as ampholytic model compounds, J. Chromatogr. A 1467 (2016) 178-187, doi:10.1016/j.chroma.2016.05.041.

[29] C.V. Hoffmann, R. Reischl, N.M. Maier, M. Lämmerhofer, W. Lindner, Investigations of mobile phase contributions to enantioselective anion- and zwitterionexchange modes on quinine-based zwitterionic chiral stationary phases, J. Chromatogr. A 1216 (2009) 1157-1166, doi:10.1016/j.chroma.2008.12.044.

[30] G. Lajkó, T. Orosz, N. Grecsó, B. Fekete, M. Palkó, F. Fülöp, W. Lindner, A. Péter, István Ilisz, High-performance liquid chromatographic enantioseparation of cyclic $\beta$-aminohydroxamic acids on zwitterionic chiral stationary phases based on Cinchona alkaloids, Anal. Chim. Acta 921 (2016) 84-94, doi:10.1016/j.aca. 2016.03.044.

[31] T. Zhang, E. Holder, P. Franco, W. Lindner, Method development and optimization on Cinchona and chiral sulfonic acid-based zwitterionic stationary phases for the separation of free amino acids by high performance liquid chromatography, J. Chromatogr. A 1363 (2014) 191-199, doi:10.1016/j.chroma.2014.06.012.

[32] M. Lämmerhofer, W. Lindner, Liquid chromatographic enantiomer separation and chiral recognition by Cinchona alkaloid-derived enantioselective separation materials, in: E. Grushka, N. Grinberg (Eds.), Advances in Chromatography, 46, CRC Press/Taylor \& Francis Group, Boca Raton, 2008, pp. 1-107, doi:10.1201/ 9781420060263.

[33] W. Kopaciewicz, M.A. Rounds, F. Fausnaugh, F.E. Regnier, Retention model for high-performance ion-exchange chromatography, J. Chromatogr. A 266 (1983) 3-21, doi:10.1016/S0021-9673(01)90875-1.

[34] C.V. Hoffmann, R. Reischl, N.M. Maier, M. Lämmerhofer, W. Lindner, Stationary phase-related investigations of quinine-based zwitterionic chiral stationary phases operated in anion-, cation-, and zwitterion-exchange modes, J. Chromatogr. A 1216 (2009) 1147-1156, doi:10.1016/j.chroma.2008.12.045.

[35] I. Ilisz, N. Grecsó, R. Papoušek, Z. Pataj, P. Barták, L. Lázár, F. Fülöp, W. Lindner, A. Péter, High-performance liquid chromatographic separation of unusual $\beta^{3}$-amino acid enantiomers in different chromatographic modes on Cinchona alkaloid-based zwitterionic chiral stationary phases, Amino Acids 47 (2015) 2279-2291, doi:10.1007/s00726-015-2006-1.

[36] I. Ilisz, Z. Gecse, G. Lajkó, E. Forró, F. Fülöp, W. Lindner, A. Péter, High-performance liquid chromatographic enantioseparation of cyclic $\beta$-amino acids on zwitterionic chiral stationary phases based on Cinchona alkaloids, Chirality 27 (2015) 563-570. 
[37] C. Czerwenka, P. Polaškova, W. Lindner, Peptide enantiomer separations: influence of sequentional isomerism and the introduction of achiral glycine moieties on chiral recognition, J. Chromatogr. A 1093 (2005) 81-88.

[38] S. Allenmark, V. Schurig, Chromatography on chiral stationary phases, J. Mater. Sci. 7 (1977) 1955-1963, doi:10.1039/a702403g.

[39] B. Koppenhofer, E. Bayer, Chiral recognition in the resolution of enantiomers by glc, Chromatographia 19 (1984) 123-130, doi:10.1007/BF02687727.
[40] T. Fornstedt, P. Sajonz, G. Guiochon, Thermodynamic study of an unusual chiral separation. propranolol enantiomers on an immobilized cellulase, J. Amer. Chem. Soc. 119 (1997) 1254-1264, doi:10.1021/ja9631458.

[41] G. Gotmar, T. Fornstedt, G. Guiochon, Apparent and true enantioselectivity in enantioseparations, Chirality 12 (2000) 558-564, doi:10.1002 1520-636X(2000)12:7〈558::AID-CHIR2〉3.0.CO;2-2. 